\title{
Evaluating User Experience for Interactive Television: Towards the Development of a Domain-Specific User Experience Questionnaire
}

\author{
Regina Bernhaupt ${ }^{1}$ and Michael Pirker $^{2}$ \\ ${ }^{1}$ IRIT, Team ICS, 118, Route de Narbonne, 31062 Toulouse, France \\ ${ }^{2}$ ruwido, Köstendorferstr. 8, 5202 Neumarkt, Austria \\ Regina.Bernhaupt@irit.fr, Michael.Pirker@ruwido.com
}

\begin{abstract}
This paper presents a questionnaire-based approach to evaluate the user experience (UX) while interacting with interactive Television (iTV) systems. Current contributions in the field of UX propose generic methods applicable to various application domains, whereas our contribution is dedicated to the specific domain of interactive TV systems. Based on a classification of UX dimensions from a literature review, the first version of the questionnaire is focusing on the dimension's aesthetics, emotion, stimulation and identification. A validation study with 106 participants was performed to assess the relations between the evaluated UX dimensions, as well as their fit to the underlying theoretical assumptions. Results showed that the UX dimensions aesthetics, emotion and stimulation are important for the domain of iTV, while identification was not confirmed. The study revealed significant correlations between the type of IPTV system used and the emotional and stimulation dimension. Additionally, a significant effect of the TV reception mode and the type of IPTV box owned on the emotion towards the system was observed. Beyond the contribution of the questionnaire that is directly applicable for any iTV system, the findings described in the paper demonstrate the need for user experience evaluation methods targeted at specific domains: the validation of the questionnaire shows that identification is not a central dimension of user experience when interacting with interactive TV.
\end{abstract}

Keywords: interactive TV, iTV, user experience, UX, questionnaire, Internet Protocol Television, IPTV, emotion, stimulation, identification.

\section{Introduction}

User experience (UX) is described as dynamic, time dependent [29] and beyond the instrumental [18]. The overall goal of UX is to understand the role of affect as an antecedent, a consequence and a mediator of technology [18]. The concept of UX focuses rather on positive emotions and emotional outcomes such as joy, fun and pride [18]. The development of a general definition of UX is still focus of scientific discourse [32], and despite the lack of a clear definition, the concept of UX has become an important design aspect of interactive systems. 
There are a growing number of methods available to evaluate user experience in all stages of the development process. Surveys on these contributions are already available such as in [3] where Bargas-Avila and Hornbæk present an overview on UX and UX evaluation methods or in [55] where Vermeeren and colleagues have been collecting and classifying user experience methods. Beyond that work on generic methods, contributions have been proposed for specific application domains, e.g. for games and entertainment [4] or for the evaluation of mobile devices like mobile phones [49].

What is still not answered is whether generic user experience evaluation methods provide meaningful and sufficiently precise insights when applied to specific application domains. In the field of usability the answer to that question was already negative [12]. Due to the idiosyncratic nature of user experience that is situational, time dependent, and influenced by the technological context especially the type of system and functionality, we advocate that there is a need to adapt, customize and validate specific UX evaluation methods for the respective application areas.

The domain of interactive TV (iTV) is described as being specific due to a variety of contextual factors, including the spatial, temporal, social, personal and technological context [42]. Beyond the difficulties brought by these factors, the evaluation of user experience for iTV is complex, as the system to be evaluated consists of multiple components: the TV screen, (a set of) remote controls, (possibly) a set top box (i.e. the hardware device connecting the TV to the IP network) and potentially other devices in the living room (e.g. surround sound system). One of the characteristics of the iTV domain is also the multiple goals of the users aiming at being entertained and informed.

We have been applying various UX methods in the area of iTV [5, 44, 45] which otherwise has received only limited attention. These studies have been carried out in close cooperation with one of the industry leaders in hardware and software systems for iTV. However, even though the evaluation results were iteratively fed into the development process of the systems, customer feedback reported by our client were exhibiting users' frustration and dissatisfaction, demonstrating a user experience far below expectations. Based on these results we have been working on the definition of a user experience evaluation method specifically adapted for iTV systems.

This paper presents the development and the validation of the first version of a user experience evaluation questionnaire called iTV-UX. The goal of the questionnaire is to enable the evaluation of all types of iTV systems in terms of user experience. The iTV-UX is based on four UX dimensions: visual and aesthetic experience, emotion and affect, stimulation, and identification.

\section{State of the Art}

User Experience (UX) is a research topic within the HCI community that has gained a lot of attention within the past years [3]. The term UX still lacks a clear and agreed-on definition. The reasons therefore are rooted in the nature of UX, which is associated within a lot of different concepts and meanings within the community, or as Law et al. [34, p. 1] put it "User Experience (UX) is a catchy as well as tricky research topic, 
given its broad applications in a diversity of interactive systems and its deep root in various conceptual frameworks, for instance, psychological theories of emotion."

Despite several attempts to define and better explain the user's experience when interacting with an interactive system in the past, the HCI community still has no unified definition of what really makes up UX, how to measure or evaluate UX, and how to rate it. An ISO Standard defining UX exists, but leaves a lot of room for interpretation, and is said to be too imprecise [24]: "A person's perceptions and responses that result from the use and/or anticipated use of a product, system or service."

Additionally, the term UX is also influenced by several concepts from other areas, like fun, playability, or Csikszentmihalyi's concept of flow [8, 26]. Within this multitude of concepts, as pointed out by Law et al. [32], the inclusion and exclusion of particular variables seem arbitrary, depending on the author's background and interest. Further reasons stated by Law et al. include the differences in the unit of analysis, ranging from a single aspect of a single user's interaction with a specific application to multi-users' interactions with a company and its services from multiple disciplines; and finally the fragmented landscape of UX research with diverse theoretical models with different foci [32]. In more recent work, Law [28] argues that the current UX researchers and practitioners may also roughly be divided into two camps, a "design-based UX research camp" which focuses more on qualitative approaches and a "model-based UX research camp" with a focus on quantitative approaches.

Similar reasons have already been pointed out by Hassenzahl [17]. He stated that the lack of agreement in definition of key elements makes building up empirical knowledge about what constitutes UX difficult, and that future research must aim at unifying approaches to UX, with its major objectives being the selection of key constructs and a better understanding of their interplay. Hassenzahl and Tractinsky [18] categorize current UX approaches and concepts in three groups:

1. Beyond the instrumental: One of the criticisms of usability evaluation was that a focus only on tasks is too narrow. Beauty as a perceptual experience, on the other hand, goes beyond the instrumental, functional concept of usability. It satisfies a human need, and was also described as an important quality of technology usage [1]. Other needs that are described as being important and should be addressed by technology include needs such as surprise, diversion or intimacy [14]. Further concepts falling into this category can be summarized as hedonic aspects of technology usage, like stimulation and identification [17]. All these UX approaches link product attributes with needs and values, the common goal is to enrich current models of product quality with non-instrumental aspects.

2. Emotion and affect: There are two basic ways in dealing with emotions in UX concepts. One way can be summarized as research that stresses the importance of emotions as consequences of product use, focusing on emotion as a result of the interaction or usage of a product. The other way concentrates on emotions that are preceding product use and contributing to the formation of evaluative judgments [18]. Current UX research rather, focuses on positive emotions and emotional outcomes such as joy, fun and pride, and also deals with emotion as a design goal [11]. 
3. The experiental: The third perspective looks at temporal and situational influences, asking for the dynamics of an interaction, how unique, complex, temporary or situated an experience is. In this view, an experience is a unique combination of various elements, such as the product and internal user states (e.g. mood, expectations, active goals), which extend over time with a definitive beginning and end. The experiential assumes all these elements to be interrelated - to interact and modify each other. The outcome of this process is the actual experience [13].

Generally, UX is described as focusing on the interaction between a person and a product, and is likely to change over time and with an embedding context $[18,32]$.

\subsection{User Experience Evaluation}

A broad variety of UX evaluation methods is available today, which are described and discussed in detail by Vermeeren et al. [55, 57] regarding their methodological approach (e.g. field studies, lab studies), the development phase they can be applied (from concepts to products on the market), the studied period of experience, and the evaluator. Law and van Schaik [33] summarize that UX measurement should essentially be self-reported, trajectory-based and adaptive, in accordance with the common understanding of UX as subjective, dynamic and context-dependent [18]. Thus, traditional techniques such as questionnaire, interview, and think-aloud remain important for capturing self-reported data [33].

Following the classification of UX approaches and concepts by Hassenzahl and Tractinsky [18], approaches focusing on the evaluation of emotion and affect include questionnaires like EmoCards [11] that ask the user to indicate the emotional state based on graphical representations. Other ways to measure the emotional response include physiological measurements (e.g. heart rate, skin conductance) or the evaluation of valence and arousal, which are currently also applied in the games area [39]. To measure the user experience beyond the instrumental, task-based approach, Hassenzahl [17] introduced the AttrakDiff questionnaire. In order to evaluate situational or temporal experiences, some approaches in mobile UX exist, using conceptual-analytical research and data gathering techniques [49]. For prototypes, usability evaluation methods can be enhanced by including experimental aspects to the evaluations, e.g. in long-term field trials, where diaries, experience sampling, questionnaires, and focus groups can be used to collect additional data [49].

\subsection{User Experience Evaluation of Interactive TV}

In the TV and entertainment sector, UX has been evaluated using a broad variety of methods. Dimensions that are addressed include emotions [36, 43], social factors [15], values and requirements $[5,42,44]$, the perception of the quality of the interaction or representation [53,47], or service quality and content [16, 31].

These user experience evaluations have been applying standard UX methods, like the AttrakDiff questionnaire [45]. Other measurements include the SUXES evaluation method, as used by Turunen et al. [53] to evaluate UX with different modalities in a 
mobile phone controlled home entertainment system. Experiences in gaming and TV applications were evaluated using psycho-physiological measurements [36]. These measurements were also used to evaluate the users' experiences with multi-view 3D displays [47] or to classify emotional reactions to video content [43]. Obrist et al. [42] investigated users' requirement and experiences within an ethnographic study and identified patterns how iTV services can support people. Tsekleves et al. [54] investigated the TV experience and media use habits using ethnographic observations. Roibas et al. [48] used ethno-methodologies like cultural probing and collaborative design to uncover the UX in future scenarios of mobile and pervasive iTV.

None of the methods applied for evaluating the overall user experience of interactive TV systems has been adapted to fit the interactive TV context. Interactive TV is special as the interaction with the system typically takes place at home, involving a certain type of setting (physical context) or influenced by people who might join the TV experience (social context) (see [42] for a discussion of the different contextual factors). While for the area of social factors and social TV Geerts and De Groof [15] have been proposing sociability heuristics, there is no adapted and validated UX evaluation method focusing on a set of UX dimensions specific for interactive TV in general.

\section{Research Goals and Approach}

Goal of our research is to develop a user experience evaluation method that allows us to evaluate the iTV specific user experience. Our research goal is motivated by the demand from the industry to have only one questionnaire combining the most important UX dimensions in this specific domain. The problem for the construction of such a method lies in the specificities of the iTV domain: it is necessary to take into account iTV characteristics and the context of usage. The user experience is shaped by interacting (using an interaction technology, i.e. a remote control, or other means of interaction) from a distance to control an interactive TV system and navigate in its menu structure, services and features. The spatial and temporal context of usage also influences the perception of the system (likely at home, at leisure time), as well as possible social factors (shared usage, co-experience). The UX of the iTV system itself is of interest, not the UX related to entertainment content.

The goal is to cover an extensive and holistic collection of user experience dimensions for the domain of iTV. The questionnaire development proceeds in three major steps, and the following methodological approach was chosen to identify the user experience dimensions used in the questionnaire and its subsequent development and iteration:

1. Identification of UX dimensions from the literature and development of a set of attributes based on existing questionnaires (presented in this paper),

2. Development and validation of the questionnaire including a set of the most important UX dimensions to verify their applicability in the domain with currently available iTV systems (presented in this paper), and finally

3. Extension of the set of dimensions to address the context specifics by adding additional dimension, and revalidation (future work). 


\subsection{Overview on UX Dimensions}

Based on a literature review, we identified publications related to UX and its dimensions, the evaluation of product experiences and UX evaluation methods from entertainment and games. Table 1 gives an overview of the diversity of UX dimensions that are referred to when describing user experience.

Table 1. Results of literature review identifying four major user experience dimensions (VM:Value/Meaning, SRC: Social/Relatedness/Co-Experience; C:Challenge; DST: Dependability/Security/Trust; SQ: Service Quality)

\begin{tabular}{|c|c|c|c|c|c|}
\hline & Aesthetic & $\begin{array}{l}\text { Emotion/ } \\
\text { Affect }\end{array}$ & Stimulation & Identification & Others \\
\hline Hekkert $2006[21]$ & $\mathrm{x}$ & $\mathrm{x}$ & & & $\mathrm{VM}$ \\
\hline Desmet and Hekkert 2007 [10] & $\mathrm{x}$ & $\mathrm{x}$ & & $\mathrm{x}$ & VM \\
\hline Alben $1996[1]$ & $\mathrm{x}$ & $\mathrm{x}$ & & & \\
\hline Hassenzahl 2004, $2008[17,19]$ & $\mathrm{x}$ & & $\mathrm{x}$ & $\mathrm{x}$ & SRC \\
\hline Karapanos et al 2010 [29] & & & $x$ & & \\
\hline Jordan $2000[28]$ & $\mathrm{x}$ & & $x$ & $\mathrm{x}$ & VM, SRC \\
\hline Wright et al 2003 [56] & $x$ & $\mathrm{X}$ & & & \\
\hline Hassenzahl et al 2010 [20] & & $\mathrm{X}$ & $\mathrm{x}$ & $\mathrm{x}$ & VM, SRC, DST \\
\hline $\begin{array}{l}\text { Jääskö and Mattelmäki } 2003 \\
{[27]}\end{array}$ & $\mathrm{x}$ & & $\mathrm{x}$ & $\mathrm{x}$ & VM \\
\hline De Angeli et al 2006 [9] & $\mathrm{x}$ & & $\mathrm{x}$ & & DST \\
\hline Steen et al. 2003 [52] & & $\mathrm{X}$ & & & \\
\hline Gaver and Martin 2001 [14] & & $\mathrm{x}$ & $\mathrm{x}$ & & SRC \\
\hline $\begin{array}{l}\text { Desmet et al 2001, Mandryk et } \\
\text { al 2006; Mahlke 2005, Minge } \\
2005 \text {, Norman } 1994[11,36,35 \text {, } \\
38,40]\end{array}$ & & $\mathrm{x}$ & & & \\
\hline Sheldon et al 2001 [50] & & $\mathrm{x}$ & $\mathrm{x}$ & $\mathrm{x}$ & VM \\
\hline McCarthy/Wright 2004 [37] & & $x$ & & & VM \\
\hline Hartmann et al 2008, [16] & $\mathrm{x}$ & $\mathrm{x}$ & $\mathrm{x}$ & & SQ \\
\hline Turunen et al $2009[53]$ & & $x$ & & & VM \\
\hline Sproll et al $2010[51]$ & & $\mathrm{x}$ & $\mathrm{x}$ & & SRC, DST \\
\hline Battarbee 2003, 2004 [2] & & & & & SRC \\
\hline Pirker et al. [44] & $\mathrm{x}$ & X & X & & VM, SRC \\
\hline Lavie \& Tractinsky 2004 [31] & $\mathrm{x}$ & $\mathrm{x}$ & $\mathrm{x}$ & & SQ \\
\hline Ijsselsteijn et al 08 [22] & $\mathrm{x}$ & $\mathrm{x}$ & & & Flow, C \\
\hline
\end{tabular}

The classification identified aesthetics and beauty, emotion and affect, stimulation, identification, meaning and value, social factors, flow, immersion, involvement and engagement; challenge; service quality and content; and dependability, trust and security. The aesthetics dimension describes how aesthetically pleasing or beautiful something is perceived. The visual/aesthetic experience deals with the pleasure gained from sensory perceptions [21]. It incorporates beauty [17], as well as classic aesthetics (e.g. clear, symmetric) described by Lavie and Tractinsky [31]. It follows 
Alben's [1] statement that objects have to be aesthetically pleasing and sensually satisfying.

Emotion has been identified as a key factor of UX [18]. For Desmet and Hekkert [10], the emotional experience is one of the three main factors contributing to product experience, including feelings and emotions elicited. Also Alben [1] addressed the factor emotion in the form of the emotional response as an outcome of the interaction. Izard [25] described ten basic emotions, of which the three clearly positive emotions were chosen to be included in the questionnaire (interest, joy and surprise), as UX is described as focusing on positive experiences [18]. Additionally, the feeling of competence as a need fulfillment is covered within this dimension [50, 20, 39].

The stimulation dimension describes to what extent a product can support the human need for innovative and interesting functions, interactions and contents. Hassenzahl [19] describes stimulation as a hedonic attribute of a product, which can lead to new impressions, opportunities and insights. Hedonic experiences were subsumed by Karapanos et al [29] under the term innovativeness to describe hedonic experiences and the ability of a product to excite the user through its novelty. In the area of games, Jääskö and Mattelmäki [27] defined product novelty as one of the qualities of user experience.

The identification dimension indicates to what extent a certain product allows the user to identify with it. For Hassenzahl [17], the identification dimension addresses the human need to express one's self through objects. Thus, using or owning a specific product is a way to reach a desired self-presentation. Identification can be seen as self-expression through an object to communicate identity.

\subsection{Developing the Questionnaire}

For the questionnaire we chose the most prominent UX dimensions to verify their applicability in the domain with currently available iTV systems: aesthetics, emotion, stimulation and identification. The decision to not include dimensions like social connectedness, interaction and value in this first version of the questionnaire is based on the current market situation for TV and I(P)TV products.

At the moment, most IPTV systems do not support social communication or services; additionally, the interaction takes place using a standard infra-red remote control. The dimension of Value might not be addressed properly in a broad evaluation of different TV systems as it is heavily influenced by the assembly of IPTV and entertainment-oriented devices and might provide better results when used in a specific setting in the future.

The questionnaire is based on a set of word-pairs for each of the dimensions identified. Each word pair represents an item of the questionnaire and is based on a seven-point semantic differential rating scale. The bi-polar adjectives used in the semantic differential scale where placed at the extremes of the scale; inversion of items was used to avoid fill-in schemes. This kind of scale was chosen as semantic differentials are described as a good choice to evaluate positive affective responses [58], which is the case for the evaluated UX dimensions. 
The dimension visual/aesthetic experience is evaluated using seven bi-polar adjectives addressing beauty, the composition (classic aesthetics) and the design of the IPTV system.

It includes items like beautiful vs. ugly, or appealing vs. unappealing. Items were based on the work of Hassenzahl [17], Lavie [31] and Desmet et al [10].

The emotional response as an outcome of the interaction and the emotions elicited are evaluated using 14 adjectives addressing the positive emotions joy, interest, surprise, and the need for diversion and competency. Seven of the items were focusing on the personal emotions (E-P) and the feeling of competence of the respondent (e.g. happy, proud, competent), and seven of the items were focusing on the emotional reaction towards the system (E-S) (e.g. pleasant, fascinating, fun). Items were based on work found in the literature [e.g. [10, 22, 25 39] and fit to the theoretical concepts.

To evaluate the stimulation dimension, the questionnaire uses six word-pairs including inventive vs. typical, or creative vs. standard amongst others. The identification dimension was evaluated using six word-pairs including premium vs. cheap, presentable vs. unpresentable, amateurish vs. professional amongst others. Item selection was mostly based on Hassenzahl's AttrakDiff [17] questionnaire and its dimensions hedonic quality - stimulation and hedonic quality - identification. To motivate respondents to respond on the basis of their concrete experiences, questions were asked in relation to their last TV usage that lasted at least 20 minutes, and also the repetition that the question is focusing on their TV system before each new UX scale in the questionnaire. The questionnaire consists of 33 items in total. It was developed in an English master version, which was then translated into [Language] for the administration of the questionnaire. The translation was checked using backtranslation by native speakers against the master version, which is described as a common way of ensuring validity in cross-cultural research [6].

The questionnaire was piloted in two steps, first using a think-aloud test, followed by pre-tests where three native speakers completed the questionnaire. Modifications resulting from the pre-tests have been incorporated in the questionnaire before its administration. Additionally, to be able to investigate differences between certain types of TV reception and the different types of IPTV set-top boxes available at the market in France, questions of how the respondents receive their TV signal and which kind of IPTV set-top box they own were added in the demographic part of the questionnaire. To get a higher response rate, and due to the fact that because of the current change to Digital Terrestrial Broadcasting, which also needs a set-top box to be received, the questionnaire was not limited to IPTV households only.

Usability of the evaluated system was evaluated using the already existing and validated SUS questionnaire. The SUS was included for further analysis of possible influences on the UX dimensions.

\section{$4 \quad$ Validation Study}

\subsection{Method}

Following our methodological approach, the aim of the study was to validate the first version of the developed questionnaire and to verify the applicability of the identified 
UX factors in the TV and IPTV domain. The questionnaire was presented as an online survey, allowing a uniform administration to a large number of respondents.

The dimensionality of the questionnaire items was analyzed using maximum likelihood factor analysis to investigate their fit to the underlying theoretical assumptions that UX in this setting can be evaluated using the UX dimensions aesthetics, emotion, stimulation and identification. This approach should subsequently inform the further development of the questionnaire, which aims to investigate domain-specific user experience dimensions in the TV and IPTV context.

\subsection{Procedure and Participants}

To validate the initial version of the iTV-UX questionnaire, the questionnaire was distributed online using the online survey tool surveymonkey.com. Participants were invited using e-mail, social networks, word of mouth and by personal invitation.

The iTV-UX questionnaire had a brief introductory section, including obligatory statements on data anonymity, followed by a series of demographic questions (age, gender) and questions regarding the TV system used (reception, type of set-top box, media usage frequency). The sections of the questionnaire - introduction, demographics and media usage, UX scales, and debriefing - were represented on individual (web) pages. The questionnaire parts addressing the UX scales additionally had a brief introductory text to highlight that participants should evaluate the most recent 20 or more minutes usage of their TV system. At the end of the questionnaire, a standard usability scale was added. Questionnaire items were randomly inverted to avoid fill-in patterns like "1111". No monetary incentives were given to questionnaire participants. Overall, the fulfillment of the whole questionnaire lasted 10 minutes on average.

Over a three week period, 106 complete datasets were retrieved. 65 participants were between 20 and 29 years, 21 participants were between 30 and 39 years, and 20 participants were older than 40 years. $59.6 \%$ were male, $40.4 \%$ female (2 participants did not name their gender). The number of persons living in the household of the person filling in the questionnaire ranged from one to six persons. $15.2 \%$ were living in single households, $46.7 \%$ of the participants lived in 2-personhouseholds, $24.8 \%$ in 3-persons-households, and $13.4 \%$ of participants lived in households with 4 or more persons $(\mathrm{n}=105)$.

The vast majority $(91.5 \%)$ of the participants watch TV at least once a week, with $64.2 \%$ watching every day, $22.6 \%$ several times a week and $4.7 \%$ of participants watching TV at least once a week. More than half of the participants (58.7\%) receive their TV signal via ADSL (i.e. IPTV), 28.8\% via digital terrestrial broadcast (TNT), 9.6\% via satellite - Pay-TV, and $2.9 \%$ via satellite without Pay-TV $(n=104)$.

The duration of the ownership of their current I(P)TV decoder was for a cumulated $83.5 \%$ more than six months, with $40.8 \%$ owning the decoder for more than 3 years; $33.0 \%$ for 1 year or more and $9.7 \%$ between 6 and 11 months. $7.8 \%$ of participants owned their decoder between 2 and 5 months, 5.8\% between one and two months, $1.9 \%$ between 2 and 4 weeks and $1 \%$ for just a week $(n=103)$. The rather large amount of new boxes can be explained by the fact that within the last half year, two 
major IPTV providers introduced the newest version of their set-top-box with new features and introductory offers.

The last TV usage situation was in $64.4 \%$ a social situation where the persons watched TV together with other persons, whereas $35.6 \%$ of participants watched TV alone $(\mathrm{n}=104)$. The last TV usage relative to the questionnaire submission date was in $92.6 \%$ of the cases within the last week, and for $73.4 \%$ of the answers even on the same day or the day before submission $(n=94)$.

\subsection{Data Analysis}

Before further analysis of the results, the inter-item reliability of questions was computed for each original scale of UX dimensions using Cronbach's Alpha [7], which indicates the extent to which questions correlate to each other. A scale is typically considered reliable if its value for alpha is above the threshold of .7. The five scales used in the questionnaire had alphas ranging from .773 to .869 (Visual aesthetics: ,861, number of items =7; Emotion System ,852, n=8; Emo Personal ,773, $\mathrm{n}=6$, Stimulation ,869, $\mathrm{n}=6$; Identification: ,783 n=6). This analysis confirms that the scales are reliable indicators of the dimensions of UX we chose to investigate.

\subsection{Factor Analysis}

The UX questionnaire was using 33 items that were evaluated on a 7 point semantic differential scale using bi-polar adjectives. The items were addressing the UX dimensions aesthetics, emotion, stimulation and identification that were identified in the literature. The dimensionality of the 33 items from the UX questionnaire was subsequently analyzed using a maximum likelihood factor analysis.

According to Kline [30], performing factor analysis requires several participants per item, where the rule of thumb lies between 4 and 10 respondents per item, with a necessary minimum of 100 participants. For our first evaluation study, 106 participants for 33 questionnaire items is slightly below the 4 person per item rule, which seems to be reasonably acceptable for a first validation study to inform the further development of the questionnaire.

Three criteria were used to determine the number of factors to rotate:

(1) the a priori hypothesis that the measures were not uni-dimensional,

(2) the initial statistics of the principal component analysis including the Scree plot, and

(3) the interpretability of the factor solutions in accordance to the theoretical UX factors framework.

The principal component analysis indicated that the initial hypothesis that the measures are not uni-dimensional was correct. The analysis yielded seven components with eigenvalues above 1, explaining $70 \%$ of the variance. Based on inspection of the Scree plot (as the results for eigenvalues bigger than 1 was no supportive indicator), we decided to carry out a subsequent factor analysis 
with maximum likelihood extraction assuming 4 factors (according to the Scree plot, where the eigenvalues were flattening out after 4 factors and the fitting with the underlying theoretical assumptions), which were rotated using a varimax rotation procedure for the UX factors that were evaluated with the $7 \mathrm{pt}$ semantic differential.

The rotated solutions yielded four interpretable factors (see Table 2) for Visual Aesthetics (VA), Emotional reaction towards the System (E-S), Emotion Personal (EP) and Stimulation (ST). The UX factors accounted for: $16 \%$ for Visual Aesthetics, $15 \%$ for Emotional - System, 13\% for Stimulation, and 9\% for Emotional Person of item variance. The factor labels from the theoretical background suited the extracted factors and were retained. A total of four items were eliminated because they did not contribute to a simple factor structure and failed to meet a minimum criteria of having a primary factor loading of .4 or above, and no cross-loading of .3 or above.

Overall, the Factorial analysis of the results of the first validation study showed that most of the evaluated UX factors were loading on the predefined factors and were fitting the assumed underlying theoretical concept. Nevertheless, the validation revealed some important insights for the further development of the questionnaire. The emotion dimension is as expected split into Emotion vs. the System and the Personal Emotion / Feeling of Competence of the respondent. The topic of identification as an UX dimension showed no clear own factor, and items that were assumed to fit into the identification dimension showed factor loadings on other dimensions in the factor analysis and were thus moved to these scales for further analysis and development of the questionnaire. The final set of items kept for the questionnaire are for Visual Aestethics (VA): beautiful-ugly; like/do not like design; appealing/unappealing, visually well-arranged/confusing; stylish/unstylish; premium/cheap; for emotional reaction towards system: fun/boring; entertaining/unamusing; pleasant/unpleasant; impressive/unimposing; exciting/lame, fascinating/uninteresting; for Emotion Personal: confident/unsure; competent/incompetent; happy/sad; proud/embarassed; for Stimulation: innovative/conservative; novel/commonplace; inventive/typical; creative/standard. All labels are translated from French.

\subsection{Correlations between the UX Factor Scales}

To investigate the interrelations between the different UX indicators, correlation coefficients (Spearman's roh) were computed among the four indicator scales. The results of the correlation analyses show that 8 out of the 12 correlations were highly significant $(\mathrm{p}<0.01)$ and all were greater or equal to 0.403 ; In general, the results suggest that the user experience factors are highly interrelated, which goes in line with the opinion of most UX researchers in the HCI community that the elements of user experience are heavily interrelated and influencing each other mutually.

Moreover, these results could be interpreted as an indicator that these UX factors or dimensions cannot be viewed independently. 
Table 2. Four Factors and their items, rev - reversed, * item indicates removed in final version

\begin{tabular}{|c|c|c|c|c|c|}
\hline Ass. Dim. & Item & & & & \\
\hline & Visual Aesthetics (VA) & VA & E-S & E-P & ST \\
\hline VA & Beautiful - ugly &, 843 & ,205 & 027 &, 162 \\
\hline VA & like the design / don't like design &, $\mathbf{8 0 3}$ &, 127 &, 018 & ,196 \\
\hline VA (rev) & appealing -unappealing & ,790 & 011 & 047 &, 214 \\
\hline VA & visually well-arranged - confusing & ,650 & ,281 &, 143 & ,193 \\
\hline I & stylish - unstylish & ,607 &, 233 &, 135 & ,264 \\
\hline I & premium - cheap & ,604 &, 313 & 073 & ,374 \\
\hline VA $($ rev $) *$ & clear lines - irregular & ,566 & 069 &, 038 &, 030 \\
\hline $\mathrm{I}(\mathrm{rev}) *$ & Presentable- unpresentable &, 563 & ,285 &,- 054 &, 218 \\
\hline $\mathrm{VA}(\mathrm{rev}) *$ & Flawless - imperfect &, 514 &, 071 &, 106 & ,197 \\
\hline \multirow[t]{2}{*}{ VA $*$} & symmetric-asymmetric & ,358 &,- 004 &,- 061 &,- 026 \\
\hline & \multicolumn{5}{|c|}{ Emotional Reaction towards System (E-S) } \\
\hline E-S & fun - boring &, 113 &, $\mathbf{8 4 3}$ &, 167 &, 148 \\
\hline E-S (rev) & Entertaining - unamusing &, 159 & ,819 &, 107 & ,095 \\
\hline E-S & Pleasant - unpleasant & ,212 & ,718 &, 250 &, 113 \\
\hline E-S & Impressive - unimposing & ,023 & ,613 &,- 009 & ,370 \\
\hline ST & Exciting - lame & ,294 &, 567 &, 038 & ,321 \\
\hline E-S (rev) & Fascinating - uninteresting & ,252 &, 529 &, 271 &, 152 \\
\hline $\mathrm{I} *$ & it fits me - doesn't fit me &, 167 & ,481 & ,205 & 073 \\
\hline \multirow[t]{2}{*}{$\mathrm{E}-\mathrm{P} *$} & Sociable - solitary &, 071 &, 353 &, 128 &, 043 \\
\hline & Emotion Personal (E-P) & & & & \\
\hline E-P & Confident - unsure &,- 039 &, 182 & ,826 &, 112 \\
\hline E-P (rev) & Competent - incompetent &,- 134 &,- 032 & ,709 & ,036 \\
\hline E-P & Happy - sad &, 139 & ,443 & ,668 &,- 035 \\
\hline E-P & Proud - embarassed & ,096 &, 361 &, 528 &,- 003 \\
\hline \multirow[t]{2}{*}{ E-P (rev) * } & Relaxed - stressed &, 142 & ,096 &, 450 &, 014 \\
\hline & Stimulation (ST) & & & & \\
\hline ST (rev) & innovative - conservative & ,289 & ,283 &,- 021 &, 868 \\
\hline ST (rev) & Novel - commonplace & ,322 & ,257 &, 004 &, 851 \\
\hline ST & Inventive - typical & ,193 & ,268 & 065 &, 763 \\
\hline ST & Creative - standard & ,307 & ,282 &, 184 & ,635 \\
\hline $\mathrm{I}(\mathrm{rev}) *$ & Professional-amateurish & ,328 &, 126 &, 078 &, 558 \\
\hline \multirow[t]{2}{*}{$\mathrm{ST}(\mathrm{rev}) *$} & Challenging - easy & 032 &,- 166 &,- 455 &, 508 \\
\hline & Other eliminated items & & & & \\
\hline E-S (rev) & good &, 386 &, 554 & 367 &, 139 \\
\hline E-S & asthonishing &,- 030 & ,416 &, 062 &, 312 \\
\hline E-S (rev) & uncommon &, 066 & ,442 &,- 123 &, 351 \\
\hline I (rev) & important for me & ,359 & ,319 &, 248 &, 375 \\
\hline
\end{tabular}




\subsection{Correlations between Usability and UX Scales}

For further investigation of the interrelations between different indicators, correlation coefficients (Spearman's roh) were computed. As a reference for usability, the questionnaire included the items from the SUS questionnaire.

The SUS rating of the system showed a significant correlation with all UX factor scales (Visual Aestethic ,447 p<0.001, ES ,642 p<0.001; EP ,528 p <0.01; ST ,271 $\mathrm{p}<005$ ). The results indicate that the usability of interactive systems remains an important issue in evaluating iTV systems and usability is influencing the overall user experience of the evaluated IPTV systems. It is important to investigate in more detail how usability influences the perception of user experience, or if the two concepts are independent.

During further investigation and correlation analysis of the SUS rating indicator, no significant correlations could be found regarding the independent variables "Type of TV Reception", "Type of IPTV Bow owned", "Period of ownership of decoder", "Age", "Sex", "Number of Persons in Household", or "TV usage frequency" and "Number of Persons in Household".

\subsection{Other Insights}

Regarding the independent variables "Age", "Sex" and "Number of Persons in Household", no significant correlation could be found for the UX indicators.

We observed no significant correlations between the UX scales and the type of TV signal reception (Terrestrial, ADSL, Satellite). Nevertheless, we discovered a significant correlation between the type of IPTV box owned and the Emotion-System scale $(\mathrm{rho}=0.346, \mathrm{p}<0.01)$, as well as for the Stimulation scale $(\mathrm{rho}=0.267, \mathrm{p}<0.05)$.

Overall, the UX ratings for the observed dimensions in our sample were rather low, but with a positive trend for the Visual Aesthetics and both Emotion vs. System and Emotion Personal dimensions. The negative trend in the results regarding the Stimulation dimension suggest that in general, TV systems are not perceived as stimulating devices. This shows that the user experience can be different for systems, even if the perceived usability is the same.

Using One-Way ANOVA on the means of the four UX scales extracted from the factor analysis, there is a significant effect of TV reception type on the EmotionSystem scale at the $\mathrm{p}<.05$ level for the four conditions $[\mathrm{F}(3,99)=2.88, \mathrm{p}=.04]$.

Post hoc comparisons using the Tukey HSD test indicated that the mean score for the satellite Pay-TV condition $(\mathrm{M}=1.11, \mathrm{SD}=0.80)$ was significantly different than the ADSL-IPTV condition $(\mathrm{M}=.17, \mathrm{SD}=1.02)$ and the TNT condition $(\mathrm{M}=.14, \mathrm{SD}$ $=.92)$. However, the Satellite (without Pay-TV) condition $(\mathrm{M}=.34, \mathrm{SD}=.76)$ did not significantly differ from the other conditions. Taken together, these results suggest that the Pay-TV offer via satellite does have a positive effect on the emotion versus the system.

Another One-Way ANOVA was conducted to compare the effect of the type of ADSL box on the on the means of the four User Experience scales extracted from the factor analysis. 
There was a significant effect of the type of ADSL box, again on the EmotionSystem Scale, at the $\mathrm{p}<.05$ level for the six conditions $[\mathrm{F}(5,52)=2.79, \mathrm{p}=.026]$.

Post hoc comparisons using the Tukey HSD test indicated that the mean score for one of the recently introduced IPTV boxes $(\mathrm{M}=1.08, \mathrm{SD}=.88)$ was significantly different than the other IPTV boxes.

As the sample size was low (58, 3 entries for 2 types of IPTV boxes were excluded), and Type II Errors are frequently in small sample sizes, additional post hoc comparisons using LSD were carried out, which resulted in a significant difference of the same IPTV box compared to all the other boxes. Taken together, these results suggest that this newly introduced IPTV set-top box which is including e.g. a BluRay Player, HDTV, a remote control that includes some simple gesture interaction and has a very elaborate design approach does have a positive effect on the emotional reaction versus the system.

\subsection{Discussion of Results}

The work reported here is clearly the first validation of the questionnaire. At current stage we have to deal with the following limitations: (1) the composition of the current sample influences the results; (2) the systems used influence the results; (3) participants answered the questionnaire not directly after the interaction with their iTV system. The clear limitation of the rather small sample size will be addressed in the next iteration of the questionnaire, which will be evaluated using a larger sample to assure the validity of the factor analysis.

The strong correlations between the UX factors up to now only show that variables are related, but not the determining influence in a particular direction. Moreover, Spearman's Roh correlations also do not state which influences are dominating determinants on particular factors. Therefore, a regression analysis will be conducted in future to come up with a model for iTV-UX, which can also be used and applied by fellow researchers in the field. This statistical model approach will enable fellow researchers to use the complete questionnaire or to focus only on specific influences, which means only a part of the UX dimensions are used. This step will be taken within the analysis of the next iteration of the questionnaire to assure validity through a higher sample size and coverage of a higher number of UX dimensions.

The extensibility of the questionnaire is critical for the development of a successful iTV user experience evaluation method, as next generation iTV system will include for instance social functionalities, new ways of representation of content and information (e.g. 3D), and also more sophisticated interaction modalities like touch, gesture or motion interaction.

\section{$5 \quad$ Summary and Future Work}

In this paper, we presented the results of a study aiming at the evaluation of a set of literature-based user experience dimensions for TV and IPTV systems using a questionnaire-based approach. The assessed UX dimensions were aesthetics, emotion, 
stimulation and identification. Results from a performed factor analysis showed that except for the identification dimensions all evaluated UX dimensions were loading on the predefined assumed factors and were fitting the assumed underlying concept. Also the factor labels from the theoretical framework suited the extracted factors and were retained; the extracted factors were labeled Visual Aesthetics, Emotion vs. the System, Emotion Personal, and Stimulation. Correlation analysis showed that the UX dimensions are highly interrelated, which goes in line with the opinion of most UX researchers in the HCI community that the elements of User Experience are heavily interrelated and influencing each other mutually. Additional analysis revealed also strong correlations of the UX scales to the Usability rating gained from the SUS scale. The assumed UX dimension identification did not show a clear own factor, the items assumed to fit into this dimensions showed mostly loadings on other factors. This suggests that identification may not be a major UX dimension for the domain of IPTV. A detailed list of the results of the factor analysis and the items used in the evaluation can be found in Table 2. Overall UX ratings for the observed UX dimensions were rather low, although all dimensions except stimulation showed a positive trend, which suggests that in general, TV and IPTV systems are not perceived as stimulating devices.

During further analysis we observed significant correlations between the type of IPTV box owned and the emotional reaction towards the system and the stimulation dimension. We also observed a significant effect of the TV reception mode on the emotion towards the system, which was significantly better for Pay-TV Systems via satellite compared to ADSL/IPTV offers and TNT. Also the type of ADSL/IPTV box showed a significant effect on the emotion towards the system, where a newly introduced IPTV set-top box which is including e.g. a BluRay Player, HDTV and has a very elaborate design approach is evaluated significantly better than other boxes.

While the usability of the systems was perceived the same for all IPTV offers, the UX evaluation indicates differences in the perception, indicating that the two concepts are different.

For our research goal to develop a questionnaire that covers an extensive and holistic collection of UX dimensions for the iTV domain, the present evaluation study was the first step. We followed our methodological approach to start with a smaller set of literature-based UX dimensions (aesthetics, emotion, stimulation and identification) and validate their applicability for the IPTV domain. Results are promising and supported our underlying theoretical assumptions that these dimension are important in this setting and measurable.

A second phase of validation with a revised questionnaire will address the identified limitations by extending the sample, ensuring that the interaction with the iTV system occurs closely related to filling in the questionnaire and by enclosing additional UX factors. These will include the value of the system for the user, social factors (shared usage, co-experience), the interaction and interaction technology, and also the perception of the quality of service. This next version aims to cover the major dimensions that are influencing the user experience in this field. When looking at recent attempts on social interactive TV systems, social factors seem to become an important factor for the evaluation of future systems. The construct of relatedness will 
be addressed together with other social factors like shared usage and co-experience. Evaluating these social factors can provide more valuable insights if future TV or connected home systems support social applications like communication. Also the ongoing development of interaction technologies that go beyond a standard button remote, e.g. by integrating gyroscopes or using touch-screens, will be considered in future versions of the questionnaire, and the interaction will be addressed as a factor influencing the UX of an IPTV system. The next iteration of the questionnaire will also incorporate entertainment-oriented UX factors like flow, as on state of the art IPTV set top boxes, games and other services are introduced and iTV systems and gaming consoles are moving closer towards each other.

\section{References}

1. Alben, L.: Quality of experience: defining the criteria for eff. interaction design. Interactions 3, 11-15 (1996)

2. Battarbee, K.: Co-Experience the social UX. In: Proc. CHI 2003 EA, pp. 730-731. ACM (2003)

3. Bargas-Avila, J., Hornbæk, K.: Old wine in new bottles or novel challenges. In: Proc. CHI 2011, pp. 2689-2698 (2011)

4. Bernhaupt, R.: User Experience Evaluation in Games and Entertainment. Springer (2010)

5. Bernhaupt, R., Pirker, M., Weiss, A., Wilfinger, D., Tscheligi, M.: Security, Privacy, and Personalization: ACM C. Entertainment 6, 2 (2012)

6. Brislin, R.W.: Back-Translation for Cross-Cultural Research. Journ. Cross-Cultural Psych. 1(3), 185-216 (1970)

7. Cronbach, L.J.: Coefficient alpha and the internal structure of tests. Psychometrika 16(3), 297-334 (1951)

8. Csikszentmihalyi, M.: Flow: The Psych. of Opt. Experience. Harper Perennial, N.Y (1991)

9. De Angeli, A., Sutcliffe, A., Hartmann, J.: Interaction, usability and aesthetics: what influences users' preferences? In: Proc. DIS 2006. ACM, New York (2006)

10. Desmet, P.M.A., Hekkert, P.: Framework of product experience. International Journal of Design 1(1), 57-66 (2007)

11. Desmet, P.M.A., Overbeeke, C.J., Tax, S.J.E.T.: Designing products with added emotional value. The Design Journal 4(1), 32-47 (2001)

12. Forbrig, P., Bernhaupt, R., Winckler, M., Wesson, J.: 5th Workshop on Software and Usability Eng. Cross-Pollination: Patterns, Usability and UX. In: Campos, P., Graham, N., Jorge, J., Nunes, N., Palanque, P., Winckler, M. (eds.) INTERACT 2011, Part IV. LNCS, vol. 6949, pp. 718-719. Springer, Heidelberg (2011)

13. Forlizzi, J., Battarbee, K.: Understanding experience in interactive systems. In: Proc. DIS 2004, pp. 261-268. ACM, New York (2004)

14. Gaver, B., Martin, H.: Alternatives: exploring information appliances through conceptual design proposals. In: Proc. CHI 2000, pp. 209-216. ACM, New York (2000)

15. Geerts, D., De Grooff, D.: Supporting the social uses of television: sociability heuristics for social tv. In: Proc. CHI 2009, pp. 595-604. ACM, New York (2009)

16. Hartmann, J., De Angeli, A., Sutcliffe, A.: Framing the user experience: information biases on website quality judgement. In: Proc. CHI 2008. ACM, New York (2008)

17. Hassenzahl, M.: The interplay of beauty, goodness, and usability in interactive products. J. of HCI 19(4), 319-349 (2004) 
18. Hassenzahl, M., Tractinsky, N.: User Experience - a research agenda. Behavior \& Information Technology 25(2), 91-97 (2006)

19. Hassenzahl, M.: Aesthetics in interactive products: Correlates and consequences of beauty, ch.11. Product Experience, pp. 287-302. Elsevier (2008)

20. Hassenzahl, M., Diefenbach, S., Göritz, A.: Needs, affect, and interactive products - Facets of user experience. Interacting with Computers 22(5), 353-362 (2010)

21. Hekkert, P.: Design aesthetics: Principles of pleasure in product design. Psychology Science 48(2), 157-172 (2006)

22. IJsselsteijn, W.A., Poels, K., de Kort, Y.A.W.: Measuring Player Experiences in Digital Games. Development of the Game Experience Questionnaire (GEQ)

23. ISO 9241, ISO 9241: Ergonomic requirements for office work with visual display terminals (VDTs)—Part 11: Guidance on usability. ISO, Geneva, Switzerland (1998)

24. ISO 9241-210, Ergonomics of Human-System Interaction - Part 210: Human-centred Design for Interactive Systems (2010)

25. Izard, L.: Die Emotionen des Menschen. Psychologie Verlags Union, Weinheim (1971)

26. Järvinen, A., Heliö, S., Mäyrä, F.: Communication and Community in Digital Entertainment Services. Online (2002)

27. Jääskö, V., Mattelmäki, T.: Observing and probing. In: Proc. DPPI 2003, pp. 126-131. ACM, New York (2003)

28. Jordan, P.: Designing Pleasurable Products. Taylor \& Francis, London (2000)

29. Karapanos, E., Zimmerman, J., Forlizzi, J., Martens, J.-B.: Measuring the dynamics of remembered experience over time. IwC 22(5), 328-335 (2010)

30. Kline, P.: The handbook of psychological testing. Routledge, London (1993)

31. Lavie, T., Tractinsky, N.: Assessing dimensions of perceived visual aesthetics of web sites. Int. Journ. of Human-Computer Studies 60(3), 269-298 (2004)

32. Law, E., Roto, V., Hassenzahl, M., Vermeeren, A., Kort, J.: Understanding, scoping and defining user experience: a survey approach. In: Proc. CHI 2009, ACM (2009)

33. Law, E., Van Schaik, P.: Modelling user experience - An agenda for research and practice. Interacting with Computers 22(5), 313-322 (2010)

34. Law, E.: The measurability and predictability of user experience. In: Proc. EICS 2011, pp. 1-10. ACM, NY (2011)

35. Mahlke, S.: Studying affect and emotions as important parts of the UX. Position Paper HCI 2005 (2005)

36. Mandryk, R., Inkpen, K., Calvert, T.: Using psychophysiological techniques to measure UX with entertainment technologies. Beh. and Inf. Techn. 25(2) (2006)

37. McCarthy, J., Wright, P.: Technology as experience. Interactions 11(5), 42-43 (2004)

38. Minge, M.: 2005. Methoden zur Erhebung emotionaler Aspekte bei der Interaktion mit technischen Systemen. Master's thesis, Freie Universität Berlin (2005)

39. Nacke, L.E., Grimshaw, M.N., Craig, A., Lindley, C.A.: More than a feeling: Measurement of sonic UX and psychophysiology in a first-person shooter game. Interact. Comput. 22(5), 336-343 (2010)

40. Norman, D.A.: Emotional design: why we love (or hate) everyday things. Basic Books, New York (2004)

41. O'Brien, J., Rodden, T.: Interactive systems in domestic environments. In: Proc. DIS 1997. ACM, NY (1997)

42. Obrist, M., Bernhaupt, R., Tscheligi, M.: Interactive television for the home: An ethnographic study on users' requirements and experiences. Int. Journ. of HCI 24(2) (2008) 
43. Oliveira, E., Benovoy, M., Ribeiro, N., Chambel, T.: Towards emotional interaction: Using movies to automatically learn users' emotional states. In: Campos, P., Graham, N., Jorge, J., Nunes, N., Palanque, P., Winckler, M. (eds.) INTERACT 2011, Part I. LNCS, vol. 6946, pp. 152-161. Springer, Heidelberg (2011)

44. Pirker, M., Bernhaupt, R.: Measuring User Experience in the Living Room: Results from an Ethnographically Oriented Field Study Indicating Major Evaluation Factors. In: Proc. EuroITV 2011, pp. 79-82 (2011)

45. Pirker, M., Bernhaupt, R., Mirlacher, T.: Investigating usability and user experience as possible entry barriers for touch interaction in the living room. In: Proc. EuroITV 2010, pp. 145-154. ACM, New York (2010)

46. Quinn, J.M., Tran, T.Q.: Attractive phones don't have to work better: independent effects of attractiveness, effectiveness, and efficiency on perceived usability. In: Proc. CHI 2010, pp. 353-362. ACM, NY (2010)

47. Rajae-Joordens, R.: Measuring experiences in gaming and TV applications. In: Probing Experience: From Assessment of User Emotions and Behaviour to Development of Products, pp. 77-90 (2008)

48. Roibás, A., Johnson, S.: Unfolding the user experience in new scenarios of pervasive interactive TV. In: CHI 2006 Extended Abstracts. ACM (2006)

49. Roto, V., Ketola, P., Huotari, S.: User Experience Evaluation in Nokia. In: Now Let's Do It in Practice - User Experience Evaluation Methods in Product Development Workshop in CHI 2008, Florence, Italy (2008)

50. Sheldon, K.M., Elliot, A.J., Kim, Y., Kasser, T.: What Is Satisfying About Satisfying Events? Testing 10 Candidate Psychological Needs. Journal of Personality and Social Psychology 80(2), 325-339 (2001)

51. Sproll, S., Peissner, M., Sturm, C.: From product concept to user experience: exploring UX potentials at early product stages. In: Proc. NordiCHI 2010. ACM, NY (2010)

52. Steen, M., Koning, N.: d. and Hoyng, L. 2003. The 'wow' experience - Conceptual model and tools. In: COST269 Conference Helsinki (2003)

53. Turunen, M., et al.: User expectations and user experience with different modalities in a mobile phone controlled home entertainment system. In: Proc MobileHCI, ACM, NY (2009)

54. Tsekleves, E., Whitham, R., Kondo, K., Hill, A.: Bringing the television experience to other media in the home: an ethnographic study. In: Proc. EuroITV 2009. ACM (2009)

55. Vermeeren, A., Law, E., Roto, V., Obrist, M., Hoonhout, J., Väänänen-Vainio-Mattila, K.: User experience evaluation methods. In: Proc. NordiCHI 2010. ACM, NY (2010)

56. Wright, P., McCarthy, J., Meekison, L.: Making Sense of Experience. In: Funology: From Usability to Enjoyment, Kluwer Academic Publ., Dordrecht (2003)

57. http: / /www.allaboutux.org/ (accessed January 20, 2012)

58. Heise, D.R.: The Semantic Differential and Attitude Research. Attitude Measurement, pp. 235-253. Rand McNally, Chicago (1970) 